\title{
Formulating Sustainable Watershed Governance Model: A Meta-analysis of Watershed Governance
}

\author{
Tri Sulistyaningsih' ${ }^{1^{*}}$ \\ Achmad Nurmandi ${ }^{2}$ \\ Muhammad Kamil ${ }^{1}$ \\ Ali Roziqin ${ }^{1}$ \\ Salahudin ${ }^{1}$ \\ Jainuri $^{1}$ \\ Iradhad Taqwa Sihidi ${ }^{1}$ \\ Ach. Apriyanto Romadhan ${ }^{1}$ \\ Mohammad Jafar Loilatu \\ ${ }^{1}$ Government Studies, Universitas Muhammadiyah Malang, Indonesia \\ ${ }^{2}$ Goverment Affairs and Administration, Jusuf Kalla School of Government, \\ Universitas Muhammadiyah Yogyakarta, Indonesia \\ ${ }^{*}$ Corresponding Author
}

DOI: https://doi.org/10.36941/ajis-2021-0041

\section{Abstract}

Currently watershed governance still involves many stakeholders from different territories, ranging from local to cross-country, and also, different social, political, cultural, and economic factors. Therefore, this study aims to categorize the themes or concepts related to watershed management studies. Through descriptive analysis and the help of the Nvivo-12 software, 383 Scopus indexed paper articles, which were published by major publishers such as Emerald, MDPI, Sage, ScienceDirect, Springer, Taylor and Francis, were obtained. The results indicate that there are 155 concepts in the watershed governance study, and they can be categorized into 6 groups. Furthermore, they are also related to dominant themes such as water resources, governance, watershed, environment, local issue, and policy. The significance of this study is the discovery of the concept of watershed governance studies; therefore, it can assist in the development of conceptual frameworks in future studies. Meanwhile, the limitation of this study is that the articles it reviewed were obtained from only the Scopus database, therefore, it does not have comparable data. Consequently, future studies need to use a comparative analysis approach which involves both the Scopus and the Web of Sciences (WoS) databases.

Keywords: Watershed Governance, Environment, Nvivo, Conceptualization 


\section{Introduction}

Watershed governance is a field of study in the disciplines of environment, ecology, sociology, and public policy (Hill et al. 2008). Furthermore, scholars in the sciences pay close attention to its study. because it is part of a global issue that has a broad influence on people's lives in any country (Rathwell and Peterson 2012). However, according to (Medema et al. 2016), the attention it receives varies as ecology and environment pay more attention to it than other fields. In regards to them, it is more related to research, experimentation, and observation, but,in the case of public policy and community empowerment, it is based on a qualitative approach which is still limited (Richards et al. 2017). Finally, according to (Pellegrini, Bortolini, and Defrancesco 2019), studies on this governance from the perspective of public policy and community empowerment is critical to support good policy making processes, and a sustainable environment.

Studies on watersheds have been conducted by many researchers, with various focuses and approaches, but none have carried out using the systematic review approach. Usually, previous studies were studied empirically through field data, using the qualitative and quantitative approaches (Hundred et al., 2014) as significant themes involving different stakeholders, some of which, manages it from a governance perspective. Nevertheless, in its management this perspective is vital because it relates to the utilization model (Craig Johnson 2001; Elinor Ostrom 2005). Watersheds studies majorly focus on the interests, process of interaction, and the decisions/policies of the various stakeholders involved. Moreover, the orientation of its use for interests, such as economic and environmental conservation, is very much determined by its governance, where the most relevant stakeholders are the central government, local/regional government, business/private groups, civil society, academics and local communities (Craig Johnson 2001). Furthermore, these stakeholders are interrelated, but often have different orientations on the use of watersheds.

\section{Theoretical Concept of Watershed Governance}

Development and management in the governance of water, land and related resources require coordination, in order to maximize equitable economic and social welfare, and the sustainability of essential ecosystems (Chen 2008). Moreover, watershed management refers to the collaboration of individual actors/government organizations to maintain the quality of water distributed to users (Hanlon 2017). The paradigm of its sustainable management challenges the need for an institutional perspective that emphasizes the exploration of various types of institutional and governance reforms. Furthermore, in general it can cross local territories, nationalities, even between countries, and private communities. Therefore, its management is very complex, as it entails various perspectives such as political processes, networks, and policies (Hanlon 2017).

Sugiyono (2016) provides the main ideas which promotes sustainable watershed management, and help to overcome the challenges of integration and holistic resource management. Furthermore, the challenges in watershed governance have significant policy implications, and offer four specific themes, including (1) A new view of water infrastructure management (2) Conservation as the basis for water management, (3) Shifting from ecosystem management to ecosystem-based management, and (4) Integrated governance and institutions at the watershed scale, that aims to help balance conflicting values, interests and priorities of water management and require progress in its governance to go beyond the fragmented sectoral approach.

Limitations in the approach used by a country, especially when its ecosystem does not fit territorially defines its political boundaries. Moreover, increasing community involvement in watershed planning, and reducing the reliance on hierarchical, and regulation-based approaches can result in greater effectiveness in policy implementation. This therefore produce better results and avoid future conflicts (Chen 2008). Due to the nature of cross-border rivers, governments need cooperate in the management of watersheds, and also involve their individual local communities in decision making processes, as the need for their implementation cannot be overemphasized. 
The benefits of community involvement, among others include: the implementation better projects that are more suited to local conditions, local people are more likely to take care of their water bodies, the potential for conflict may be limited, and the local communities will be empowered (Patricia E. Perkins 2017). From a different perspective, (Rathwell and Peterson 2012) offered new management mechanisms for water governance, and they include: transboundary water management practices which are characterized by sovereignty disputes, diverse political interests, dynamics between central and local governments, and the relationship between government and society. Lastly, water resources occur in the context of complex physical and institutional systems.

In implementing an ecological approach, there is a tendency for practitioners to continually interpret it as being synonymous with the comprehensive approach, where all components and linkages in the ecosystem are considered (Chilima et al. 2013). Meanwhile, in developing Water Governance, Imperial (2005) emphasizes the challenges of sustainable water governance, the importance of improvising governance networks through effective institutions, and the implementation of public policies in a world of shared power and authority. In addition, one of the implementation strategies used in network settings is collaboration.

The following are a range of critical issues affecting municipal involvement in governance at the watershed scale, are widely applied in a variety of different contexts, and which deserves more attention in future research: (1) disconnection and ambiguity of authority across levels of the hierarchy, (2) internal and external challenges for cities involved in effective collaboration, (3) barriers to expanding the scope of traditional urban functions, and (4) biophysical, institutional, and political time frame mismatches.

In recent years, studies on watershed governance, including that by Mumme (2020), which took a case study of the agreement between the USA and Mexico in 1944 , have focused more on the process and importance of maintaining water supply as a city resource (Hanlon 2017). Furthermore, Marshall \& Duram (2017), while following the perspective of local stakeholders explained that experience and education are useful evaluation tools in watershed management. The results of that study indicate that the level of education has an effect on community participation. Moreover, still from a local perspective, (Koontz and Thomas 2018) focused on the forms of science-based environmental policies and collaborative efforts, especially watershed management.

Studies in regards to watershed are increasing along with institutional efforts to maintain the availability of water resources in the future. Therefore, this study was simplified to the study of water resistance (water security). This is evidenced in the study by Empinotti (Empinotti, Budds, and Aversa 2019), on the experience of the water crisis in Sao Paulo, Brazil, which provides a general lesson that water management is important to minimize the occurrence of crises in the event of a long drought. In addition, its importance will further be evidenced when climate change and global warming have direct impacts on countries with tropical climates, since it might be the only solution when crisis occurs.

Based on the complexity of the problems associated with watershed management in various studies, and the numerous number of actors, perspectives and approaches used to analyze its management problems, it is essential to categorize the various related concepts and themes that are often discussed in its studies. Moreover, this categorization, it will help further studies focus on a particular concept, even when it has never been discussed.

\section{Systematic Review Methods}

This study aims to review various scientific articles discussing watershed governance, that have been published in reputable international journals. In addition, the review article in this study is directed at conceptualizing the study of watershed governance, which is explained through the following questions, namely: (1) What is the relationship and clustering of themes in watershed governance studies? (2) What is the dominant theme in watershed governance studies? (3) Which are the related topics of watershed governance studies? (4) What type of mapping is used in watershed governance 
study topics? (5) What concepts are used in the study of watershed governance? These questions are explained based on the topic of study, framework, and previous research findings indexed in the Scopus database. Articles are reviewed in this study through the following stages (1) article search and (2) topic mapping.
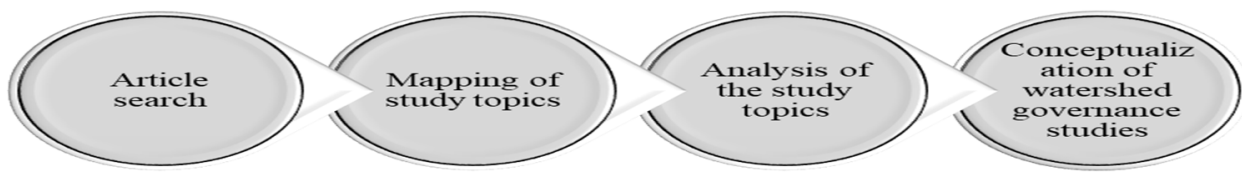

Chart 1. The Article review process

Articles were searched for through the following stages. First, article identification. This was carried out by publishing or perishes software, using the Scopus database. Furthermore, during this stage, the keyword "watershed governance" was inputted into the article search column in the publish or perish application, and the year of publication was limited to between 2017 and 2020. This search resulted in the display of 1350 articles which were relevant to the topic. The second stage was article verification. Here the articles were inputted into the excel table, and were verified based on the criteria for their relevance, article $\mathrm{H}$-index, and study on midwives that emphasize the area of environment, public policy, spatial planning, water resources, society, and ecology. In addition, the article verification resulted in 500 articles, which were considered to have a high level of relevance to the research topic. Moreover, of the verified articles, only 383 which were selected based on the availability of full-text articles in the database of each journal were analyzed. The final sage involved downloading the full text of the articles. Here, the full texts, were downloaded to the respective journal databases which published them.

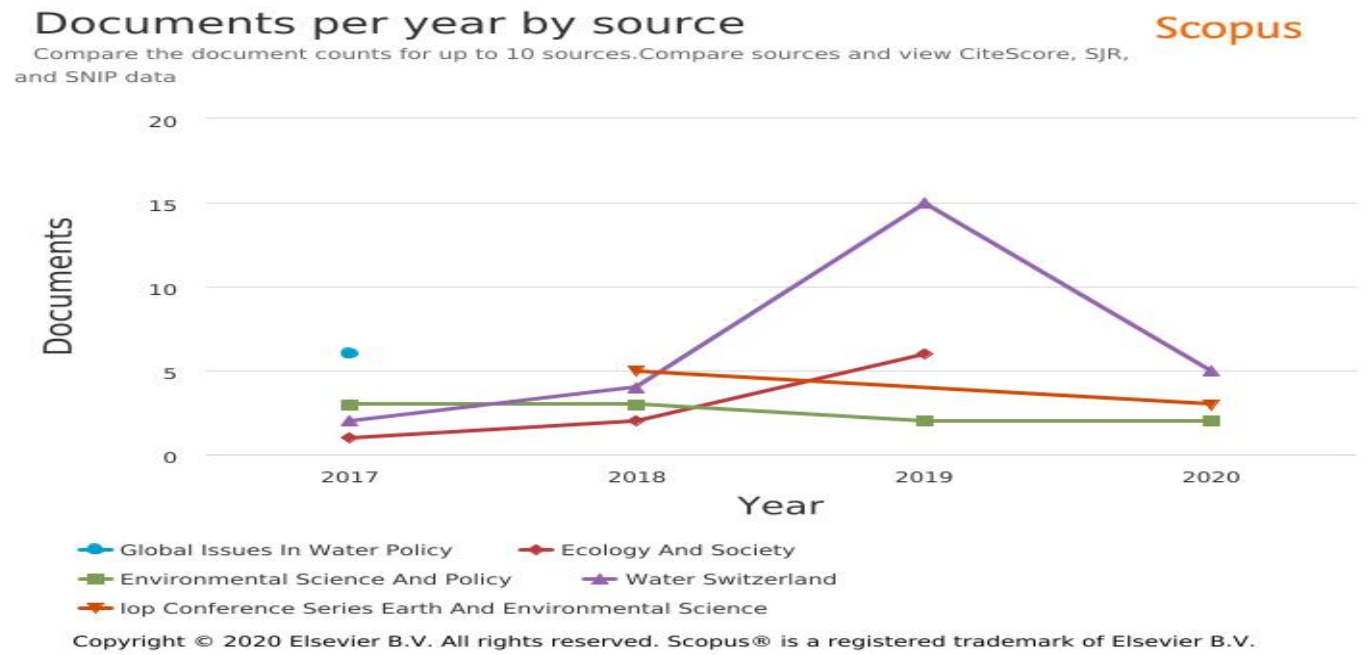

Chart 2. Articles based on the theme of watershed governance 
The mapping stages in this study were carried out through the following process-first, the full-text articles were imported into the VOSviewer and NVivo 12 plus software. This process was carried out to obtain clusters of data, and to visualize the networking of the study theme. Meanwhile, the Nvivo 12 plus software was used to input the topic of study, the relationship between the study themes, and their mapping, based on the focus of each article analyzed. Second, the articles were managed in the Nvivo 12 plus software, by classifying them based on their author, year, journal, and publisher's name. Furthermore, this classification was carried out using the NVivo 12 plus database import feature.

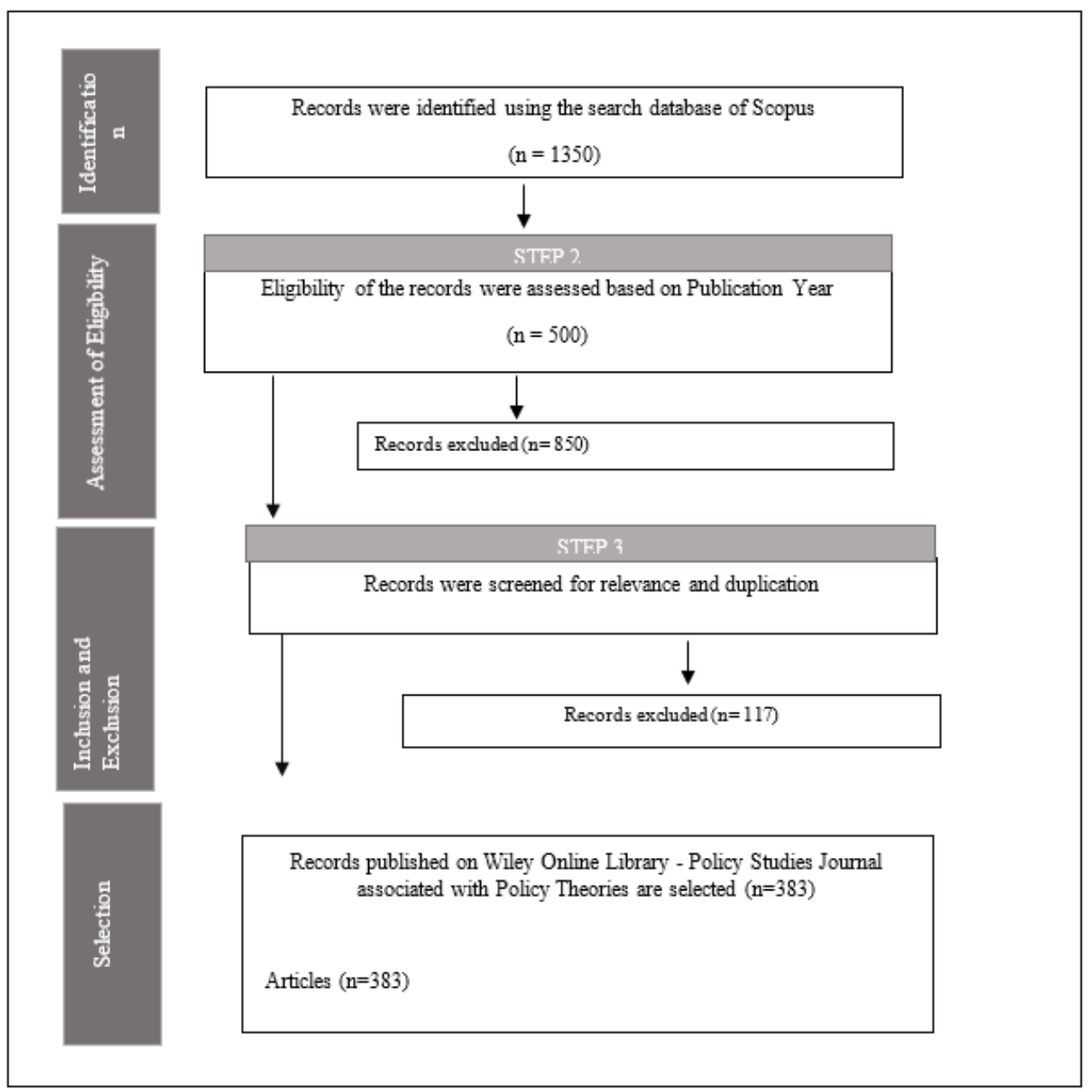

Chart 3. Stages in searching and selection of articles

The stages of the data analysis and conceptualization are the article review stages that produce data which can answer the study questions. Moreover, at this stage, data analysis is focused on cluster analysis, dominant topics, linkage of themes, and mapping of watershed governance study topics, based on the 389 articles analyzed. Finally, this analysis was aimed at producing a watershed governance study concept that is formulated based on the articles reviewed. 


\section{Review of Results and Discussion}

\subsection{Linkage and Clustering of Themes in Watershed Governance Studies}

In this section, concepts were explained in several visualizations related to the theme of this study, and 155 of them were identified in the 383 articles. Furthermore, the results of their reviews with VOSviewer revealed that there were six concept clusters (see table 1). Figure 1 shows the names of the concepts which were derived from the cluster density display. Furthermore, the colour code used for each of them was used to view a list of the concepts that stand out from each cluster. The aim is to identify as many themes as possible that are often discussed in previous studies, and allow them to be used in future studies. Taking a look at Figure 1, it shows the density of the clusters which are distinguished by a different colour from each cluster.

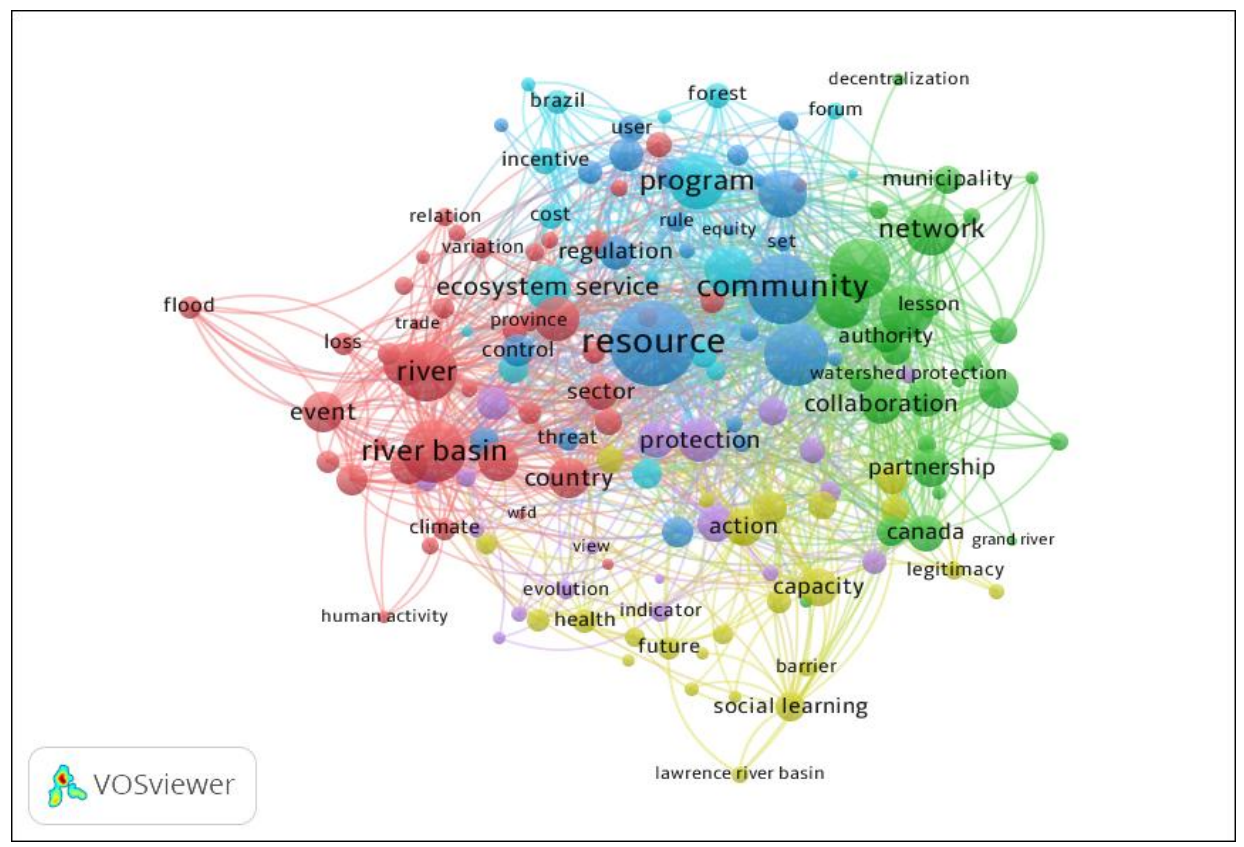

Figure 1. Relation of themes in watershed governance studies

The identification in the form of mapping in Figure 1 can help researchers, especially the new ones begin their research with a head start. When they find a topic of interest in a particular area, they are curious about, they can read articles related to that topic with the help of this study. In Cluster 1, the related concepts are river basin management, land-use change, and environmental governance, while Cluster 2 emphasizes the concept of watershed governance, actor collaboration, and local government. In the case of Cluster 3, concepts are to community and regulation, and as for Cluster 4, they focus on collaborative governance. Furthermore, Cluster 5 focuses on interaction and evolution, while Cluster 6 , on programs and ecosystems. For researchers who want to discuss the theme of watershed governance, this clustering will help analyze what concepts are related. For example, when a researcher chooses cluster 2, the starting point that needs to be the body literature is the concept of watershed governance. Furthermore, researchers can also search for related literature in the reference manager, with keywords that fall into the category of cluster 2, which are collaboration, participation, actor, authority, and more. 
Table 1. Themes clustering in watershed governance studies

\begin{tabular}{lll}
\hline Cluster & Concept Name & Total \\
\hline Cluster 1 & $\begin{array}{l}\text { River basin, river basin management, land use change, flood, green infrastructure, human activity, } \\
\text { climate, poverty, loss, risk, effect, adaptive capacity, cooperation, environmental governance. }\end{array}$ & $4 \mathbf{4 1}$ \\
\hline Cluster 2 & $\begin{array}{l}\text { Watershed governance, collaboration, participation, network, actor, authority, coordination, } \\
\text { leadership, initiative, collaborative approach, local government, accountability, partnership, }\end{array}$ & 27 \\
\hline Cluster 3 & Resource, community, institution, conflict, local community, law, politics, regulation, rule, control. & $\mathbf{2 5}$ \\
\hline Cluster 4 & $\begin{array}{l}\text { Social learning, barrier, integration, capacity, future, vision, health, legitimacy, collaborative } \\
\text { governance, decision making. }\end{array}$ & $\mathbf{2 5}$ \\
\hline Cluster 5 & Participant, interaction, survey, protection, evolution, supplay, demand. & 19 \\
\hline Cluster 6 & Program, decision, forest, watershed services, cost, ecosystem services, territory. & 18 \\
\hline
\end{tabular}

In the case of Cluster 1, which is related to river basin management, the relevant article as a reference would be for example, one written by Goh (2019), which explained that flood problems are often caused by poor management in the watershed, land development, and water infrastructure. Furthermore, this study, which was conducted in Jakarta, looks at flooding from a city governance perspective, that includes planning and maintaining infrastructure, and land use. In addition, the flood phenomenon and the relationship between political ecology and environmental ethnography herein are connected socio politically.

In Cluster 2, watershed management requires collaborative efforts and the involvement of all actors in decision making. Overduin and Moore (2017) in an article entitled "Social license to operate: Not a proxy for accountability in water governance", and published in the Geoforum Journal, explained that the accountability process of each actor could use a social license and emphasize community involvement. However, it cannot be considered a measure of accountability in watershed management. Another related article is one by Wang, Tong, \& Li (2019), which explained that the inter-organizational characteristics of watershed governance have generated numerous problems from the capacity of each department. Furthermore, a study conducted in China discovered problems related to hierarchical systems and vertical coordination. Finally, future studies need to pay attention to legal aspects, integrated watershed management, and increase community participation.

Cluster 3 is related to the concept of politics and policy, and an example of it can be found in the article by Ward et al., (2017). This study which was conducted on the Yellowstone river management locus explained that the State has a role in a reformative manner for the integration of watershed management. Meanwhile, the study by Brinkman et al., (2012), where a quantitative approach was used, after measuring the role of collective action, and community empowerment, suggests that community capacity, must be handled in watershed management .

In a case where the researcher chooses to use cluster 4, it is noteworthy that the articles related to it are those that dwell on collaborative governance (Weible 2011) and related things, such as legitimacy. Meanwhile, concepts in cluster 5 are related to water resources protection through participatory management, and can be seen in the article by Sikka (2009) which focused on Exploring options of participatory water management for livelihood improvements in the Indo-Gangetic Basin. Finally, an example of an article related to Cluster 6 is that by Huber-Stearns and Cheng (Huber-Stearns and Cheng 2017), which explained that human development and an increasingly complex environment requires collaborative policies and programs, such as IWS (Investments in Watershed Services). In addition, with this program, the federal or local governments can further strengthen watershed services.

\subsection{The Dominant Theme in Watershed Governance Studies}

Word Frequency Queries, explores words that appear most frequently in research data. Therefore, with this analysis tool, words that have the same meaning can be categorized in the same group. Based on the results of data analysis sourced from the 383 articles, the dominant themes studied by previous researchers were management, watershed, governance, environmental, local, policy and resource 
themes. Therefore, it can be interpreted that these are the entire focus of research in regards to this topic. This is further explained in (Figure 2), especially on the words in bold.

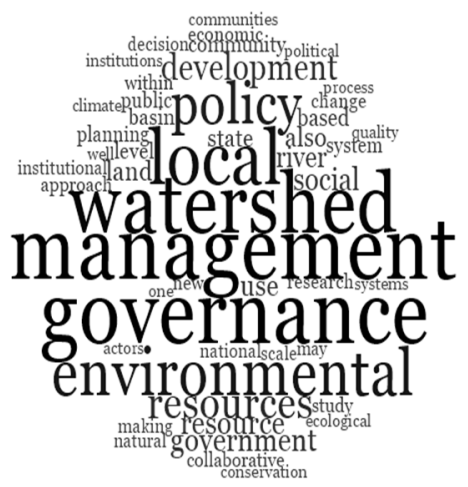

Figure 2. The dominant theme in watershed governance studies

It is necessary to pay close attention to words such as government, communities, and institutional, which are also important, considering that the management of the watershed is a very complex multidimensional system, because it crosses the national territory, State, district, city, village, and involves various other interest groups. Furthermore, the complexity of its problems and the large number of actors involved leads to many competing issues and interests in its management, such as well-level, ecological, quality, climate and conservation. Therefore, its management needs to be collaborative.

\subsection{The Categorization of Watershed Governance Study Themes}

Based on the cluster analysis with NVivo 12 plus sourced from 383 Scopus indexed articles, there are six main clusters in the watershed governance study (see Figure 3), namely water resources, governance, watershed, environmental and policy. Furthermore, the results of the categorization of the study themes indicate that study on this governance discusses a lot about the six themes.

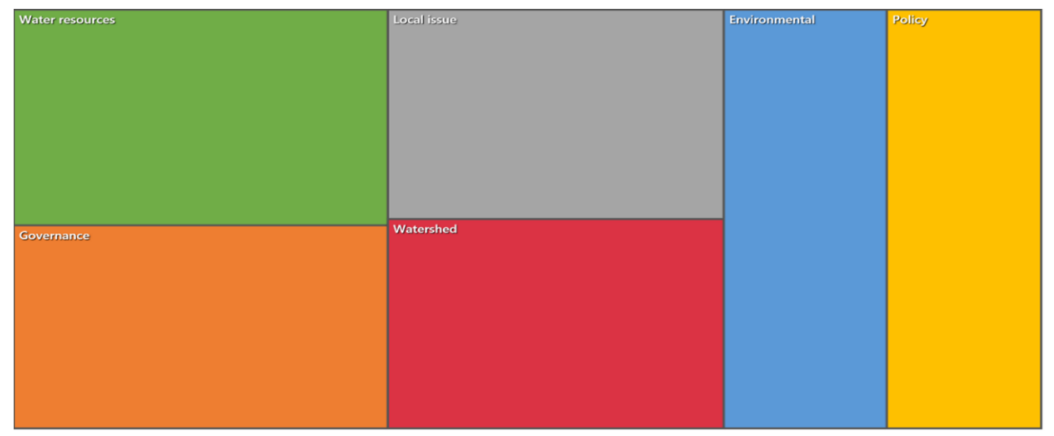

Figure 3. The categorization of watershed governance study themes

The theme of this study discusses water resources, as the most effective natural resource management, and also suggests that it requires strengthening in order to ensure sustainability. Traditionally, the concept of sustainability is associated with a triple bottom line framework, which consists of economic, environmental and social dimensions. Therefore, a well-integrated water management framework is needed, in order to ensure that information on water needs and availability is obtained (Borrego-Marín and Riesgo 2016; Ferreira, de Lima, and Corrêa 2020). Water governance requires cooperation that 
involves a shift in emphasis from government control to voluntary arrangements that directly involve non-state stakeholders in decision making (Medema et al. 2016), one of which is through community involvement in watershed management, for the conservation of water resources (Brinkman et al. 2012).

The theme of governance studies in the discussion of watersheds can be understood as the adjustments to watershed management made by altering the scale of governance and managed resources and organizations that have authority over the management of these water resources. Furthermore, the complex institutional layer, combined with the changing political context creates new challenges in the management of these resources. Conducting institutional reform and building comparative understanding are one of those things needed to build institutional suitability in carrying out watershed management (Ulibarri and Garcia 2020). In addition, the complexity of this management requires the formation of collaborative partnerships within the framework of a political contract.

It can be understood from the theme of local issue studies on watersheds that its management policies vary according to location, approach and interests between each actor. Therefore, these policies must be adapted to the local ecological, cultural, social and political context. Experience in watershed management at each location needs to be obtained in response to concerns about the sustainability of the watershed. Furthermore, learning lessons from experiences and transferring them elsewhere is an established practice for addressing watershed governance challenges. For example, this can be carried out combining by local knowledge and experiences in policy-making (Baird et al. 2014), or by paying attention to local-based decision making processes for local land use.

The theme of this study suggests that water resources management policies are faced with factors such as uncoordinated national development policies, weak institutional frameworks, and top-down management. Therefore, it is necessary to design or model an integrated watershed management policy, such as through a collaborative approach, with attention to population, size, the significance of problems, institutional arrangements, and focus of activities, since it will help policymakers better understand the challenges and types of collaboration that are appropriate (Margerum 2008).

It can be understood from the relationship between watershed and environmental and water resources that watershed management is increasingly influenced by the principle of sustainability, which is a horizontal integration that is stronger from the social, economic and environmental dimensions. Furthermore, the capacity of a watershed is not always the same as it changes as a result of being influenced by population growth, changes in land use, soil erosion, and poor governance. Consequently, it causes an increase in poverty, environmental degradation, and a decrease in ecosystem services (Elisa, Gara, and Wolanski 2010). Considering the above it is concluded that watershed requires sustainable basic management, such as through the Integrated Watershed Management (IMW) approach (Arteaga et al. 2020), and the principles of ecohydrology (Elisa, Gara, and Wolanski 2010).

\subsection{The Relationship Between the Topics of Watershed Governance Studies}

Results of the review of the 383 articles using Nvivo 12 plus shows that there is a strong relationship between the topics of watershed and water resources, governance, local issues, environmental, and policy (Table 2). Although this relationship has different Jaccard coefficient values, that between watershed and the five study topics confirms that this study is one that cannot be separated from the topics of water resources, governance, local issues, environment, and public policy (Lin, Thornton, and Shadrin 2015; Patterson et al. 2012; Koontz and Thomas 2018).

Table 2. Relation of watershed governance study topics

\begin{tabular}{llc}
\hline Code A & Code B & Jaccard's coefficient \\
\hline Watershed & Water resources & 0,744681 \\
\hline Watershed & Governance & 0,718499 \\
\hline Watershed & Local issue & 0,686649 \\
\hline Watershed & Environmental & 0,685637 \\
\hline Watershed & Policy & 0,663102 \\
\hline
\end{tabular}


The relationship between watershed and governance can be understood as an integrated governance process which include (1) merging areas that are large enough to address downstream problems and cause extra-local effects on smaller watersheds, (2) locally-based decision making for local land use, (3) technical resources for local agencies, and (4) procedures for synthesizing data vertically (up administrative hierarchy structures) and horizontally (between local units), to regulate watershed land use from upstream to downstream levels (James Adams, Ezrow, and Wlezien 2015). In addition, such a system must have the institutional capacity to effectively regulate land uses that affect water quality, in order to ensure that the resulting watershed plan has a high degree of compliance.

From the relationship between watershed, local issues and policies it can be better understood that watershed management policies vary according to location, and the approaches and interests of each actor. Therefore, these policies must be adapted to the local ecological, cultural, social and political context. Experience in watershed management at each location needs to be obtained in response to concerns about its sustainability. Furthermore, learning lessons from experiences and transferring them elsewhere is an established practice for addressing watershed governance challenges. This can be carried out by, for example combining local knowledge and knowledge in policy-making (Baird et al. 2014), paying attention to local-based decision making processes for local land use, and using technical resources for local agencies (Jane Adams et al. 2005). In addition, learning from these insights offer opportunities to advance the development of new approaches, as well as improve existing watershed management policies.

\subsection{Mapping of the Theme of Watershed Governance Studies}

The results of the review of the 383 articles using the matrix framework feature and the NVivo 12 plus project map feature revealed that, in general, studies on the theme of watershed governance are related to 5 main topics, namely local issues of the watershed, public policy, governance, environment and water resources. Furthermore, each of these themes is derived from several explanatory indicators.

The topic of local issues on the watershed is significantly influenced by the process of power relations that occurs between the government and all its authorities that are attached to the people whose lives are directly related to the watershed. Furthermore, it is related to how local conflicts occur due to watershed management or water sources, the mechanism implemented by local authorities as watershed managers works in environmental conservation planning, trust in policy and financial support carried out by local governments, and how government activities lead to the formation adaptive policies in watershed management. One of its essential objectives is how to involve the participation of all stakeholders (government and society) in watershed management (Eden et al., 2016), in order to ensure that the resulting policy accountability is more evidenced (Overduin and Moore 2017). Furthermore, public policy is related to the design and model of the watershed management policy being used.

Some of the models in question show the high involvement of local community participation in the process of formulating watershed management policies, as well as in the adaptability of the government to accommodate the community demands through implemented policies. Furthermore, the involvement of the private sector, such as companies, is also needed in order to ensure that economic interests and environmental sustainability are taken into consideration during management (Milman and Warner 2016). In general, the accountability that occurs as a result of the collaborative process between the government and the community has led to the desire to integrate watershed management as part of environmental conservation policies, in order to ensure that the sustainability of life is maintained in the future. Finally, in this case, the policy management adopted is able to unite the interests of all related stakeholders (Zeitoun, Goulden, and Tickner 2013).

Governance is related to the process of working with government principles in regulating and managing watersheds. Furthermore, with regard to the strategic actors involved (state and non-state actors), the ongoing power relations, the strategies used and the effectiveness of the resulting policies, the primary key for effective governance is collaboration, as it ensures that all related actor actions are 
coherent. A democratic model like this will result in the creation of policies that are effective in harmonizing the use of watersheds for the sustainability of biological and human ecosystems (de Oliveira Faria and Magrini 2016). Meanwhile in a complex Watershed governance regime, integration is needed, and it is only possible through intensive collaboration between government, academia, community and development consultants (Schweizer 2017).

Environmental relates to a perspective that considers watershed as part of a strategic environmental issue because it is a living ecosystem, in which there are human interests, and environmental sustainability and integration is essential. Therefore, the perspective about the environment needs to be directed at the principle of sustainability, by making an accountable environmental reform policy, in order to ensure that it is more environmentally friendly. When this has been carried out, environmental conflicts can be avoided, and the watershed sustained. In Peru, the success of good forest management is obtained through participatory policy design and intervention, especially by local communities (Hajek et al. 2011). In addition, high emotional ties and critical knowledge about forest management emphases the need for local communities (communities) to be involved in the management procedures (Morzaria-Luna et al. 2020), because their local wisdom enables them to conserve the forest and consequently maintain the quality of river water. Meanwhile, water resources consider watershed a commodity that is useful for many purposes, such as being a resource, for consumption, conservation, population growth, health and profitability. In order for all interests to be accommodated, strict and fair regulatory certainty is needed. Furthermore, it is necessary to harmonize power between the central and local (federal) governments, with the aim of not overlapping regulations, in order to ensure that water governance is more integrated and inherent with all interests. One thing of note is social participation, as it makes it easier for justice and equality to be realized in water resource management (Siders 2019). Moreover, it involves the presence of nonstate actors such as local communities.

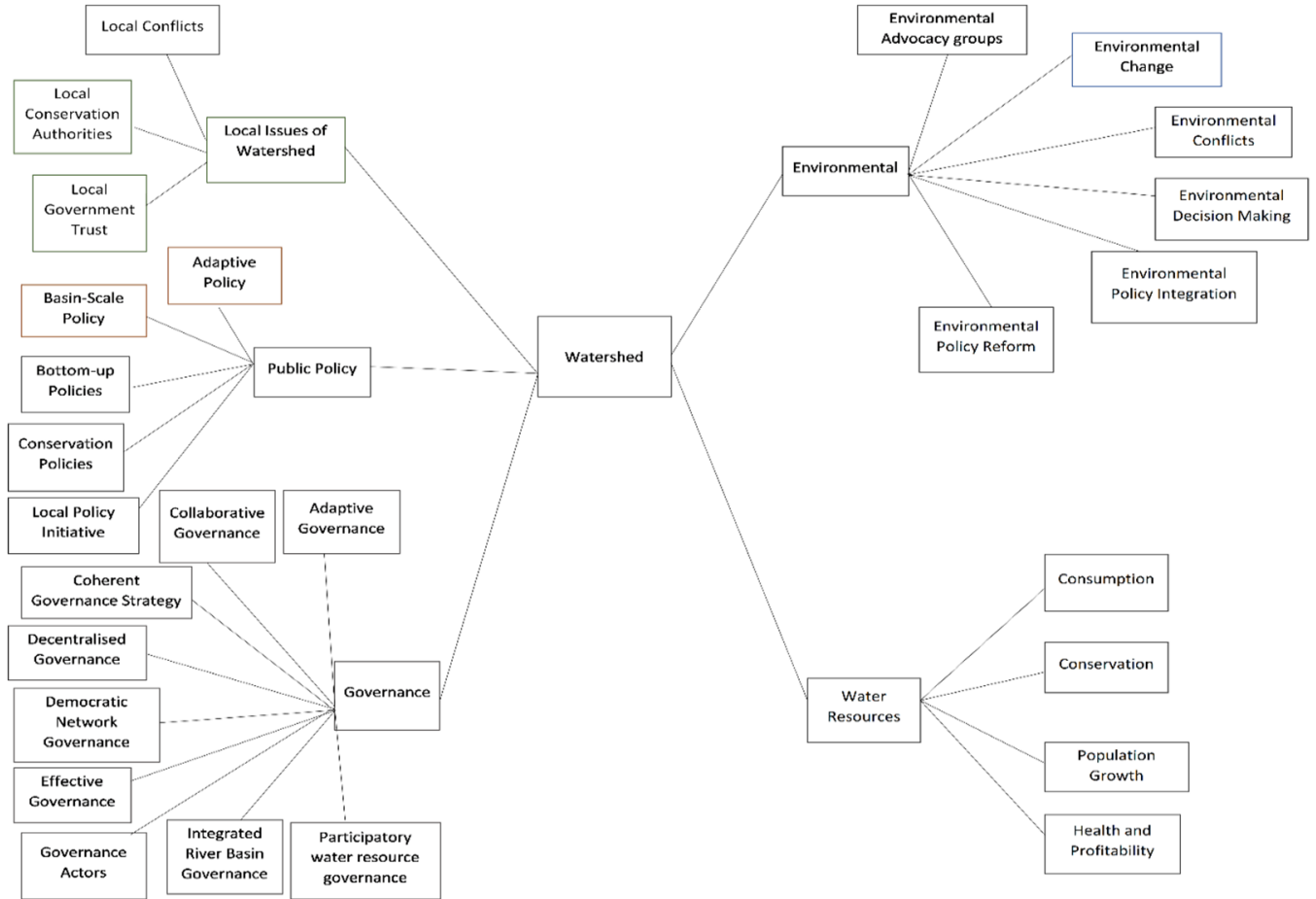

Figure 4. The formulation of watershed governance model 
Figure 4 above shows that the watershed theme has very broad, complex and interrelated dimensions. Furthermore, due to that it is a part of the environmental issues which provide many benefits to human life, the key to its management is very dependent on the capacity of governments to formulate watershed utilization policies. Finally, participatory and collaborative approaches are needed in order to ensure that watersheds do not generate conflicts through, strict regulations and fair policies.

Sustainable watershed governance is the outcome of the interaction between actors, networks, and good rules of the game within a governance framework. This governance is also influenced by good conservation policies. However, a good conservation policy must be supported by good institutions. What is meant by institution is formal and informal norms that shape the attitudes and behavior of actors (Ingold 2011). This institution starts from regulations that form norms and ultimately results in a good conservation culture that is understood and implemented by all actors involved.

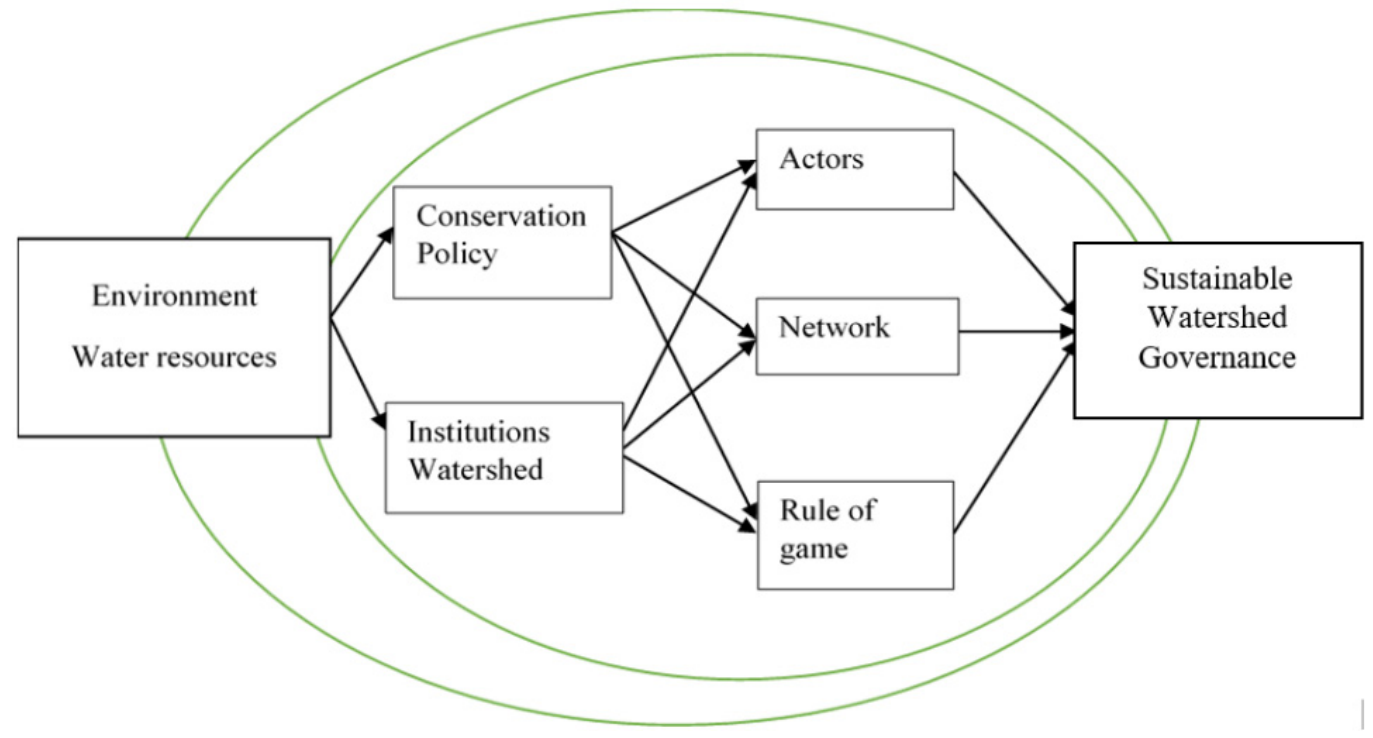

Figure 5. Proposed Sustainable Watershed Governance Model

Connectivity in science in the study of watershed governance leads to scientific efforts in realizing sustainable river-flow management. Figure 5 is a sustainable river-flow management model formulated based on the watershed governance study field's connectivity, consisting of input, process, and output. Watershed governance inputs are environmental and water resources problems. The watershed governance model method is related to the concept of conservation policies, institutions, the role of actors, networks, and legal norms. Then, the output model of watershed governance is the formation of sustainable river-flow management. This model can be used as a map of scientific studies in watershed governance studies, consisting of three study areas: the input, process, and output areas. The study of watershed governance's input areas are environmental problems, water resources, and river flows used as objects of study on watershed governance. The watershed governance study process is a watershed governance study that is explained based on the perspective of environmental conservation policies, institutions, the role of actors, legal regulations, cooperation, and collaboration networks. The area of the watershed governance study process is directed at achieving the study output, which describes sustainable river-flow management, which this section is the output area of the watershed governance study. 


\section{Conclusion}

This review study dwells on watershed governance which covers 6 clusters and has five main topics. Furthermore, it shows that there were 155 concepts in the 383 articles obtained from the Scopus database. The results of the review with VOSviewer showed that there are six concept clusters, namely, Cluster 1, where the related concepts are river basin management, land-use change, and environmental governance, Cluster 2 which emphasizes the concept of watershed governance, actor collaboration, and local government, Cluster 3 which is related to the community and regulation, Cluster 4, which focuses on collaborative governance, Cluster 5 , which dwells on interaction and evolution, and finally Cluster 6, focuses on programs and ecosystems. Moreover, the dominant themes studied by previous researchers are grouped into six main categorizations namely, water resources, governance, watershed, environmental and policy. Finally, there are five topics that have strong ties to that of watershed governance, namely water resources, governance, local issues, environmental, and policy.

This study contributes to the mapping of watershed governance studies, which provides an overview of the dominant topics being dwelled on. In particular, this topic explains how watershed governance from a governance perspective contains the interests and behaviour of the related actors, such as the government, civil society, society and the private sector. Finally, good management which emphasizes the use of watersheds as part of environmental conservation is the answer to conflicts in watershed management.

The primary key to good watershed management is participation and collaboration. Furthermore, the government which is the centre of power in watershed management, needs to involve both public and private participation in the form of positive synergies, in order to prevent future environmental conflicts and crises. For this reason, a strong watershed protection regulation is needed in order to ensure that its political legitimacy increases. Moreover, in order to avoid overlapping regulations, policy synchronization between the central and regional governments is absolutely necessary. While, in the use of watershed for economic interests, local community participation is also needed, as it ensures that there is an integration between the economic and social interests of the community.

The limitation of this study is that the articles it reviewed were only sourced from the Scopus database, therefore, it does not have comparable data. Consequently, the next study needs to use a comparative analysis approach which involves both the Scopus and the Web of Sciences (WoS) database.

\section{References}

Adams, James, Lawrence Ezrow, and Christopher Wlezien. 2015. "The Company You Keep: How Voters Infer Party Positions on European Integration from Governing Coalition Arrangements." American Journal OfPolitical Science oo (o): 1-13. https://doi.org/10.111/ajps.12231.

Adams, Jane, Steven Kraft, J B Ruhl, Christopher Lant, Tim Loftus, and Leslie Duram. 2005. "Watershed Planning: Pseudo-Democracy and Its Alternatives - The Case of the Cache River Watershed, Illinois." Agriculture and Human Values 22 (3): 327-38. https://doi.org/10.1007/s1046o-005-6049-X.

Arteaga, Juan, Pablo Ochoa, Andreas Fries, and Jan Boll. 2020. "Identification of Priority Areas for Integrated Management of Semiarid Watersheds in the Ecuadorian Andes." Journal of the American Water Resources Association 56 (2): 270-82. https://doi.org/10.1111/1752-1688.12837.

Baird, Julia, Ryan Plummer, Samantha Morris, Simon Mitchell, and Kaitlyn Rathwell. 2014. "Enhancing Source Water Protection and Watershed Management: Lessons from the Case of the New Brunswick Water Classification Initiative." Canadian Water Resources Journal 39 (1): 49-62. https://doi.org/10.108o/o7011784.2013.872872.

Borrego-Marín, María M., and Laura Riesgo. 2016. "Measuring the Sustainability of Water Plans in Inter-Regional Spanish River Basins.” Water (Switzerland) 8 (8). https://doi.org/10.3390/w8080342.

Brinkman, E., E. Seekamp, M. A. Davenport, and J. M. Brehm. 2012. "Community Capacity for Watershed Conservation: A Quantitative Assessment of Indicators and Core Dimensions." Environmental Management 50 (4): 736-49. https://doi.org/10.1007/soo267-012-9922-6.

Chen, Sulan. 2008. "From Community-Based Management to Transboundary Watershed Governance." Development 51 (1): 83-88. https://doi.org/10.1057/palgrave.development.1100445. 
Chilima, Jania S., Jill A.E. Gunn, Bram F. Noble, and Robert J. Patrick. 2013. "Institutional Considerations in Watershed Cumulative Effects Assessment and Management." Impact Assessment and Project Appraisal 31 (1): 74-84. https://doi.org/10.108o/14615517.2012.760227.

Craig Johnson. 20o1. "Local Democracy, Democratic Decentralisation and Rural Development: Theories, Challenges and Options for Policy.” Development Policy Review 19 (4): 521-32.

Elinor Ostrom. 2005. Understanding Institutional Diversity. New Jersey:Princeton University Press.

Elisa, Manase, John Ignase Gara, and Eric Wolanski. 2010. “A Review of the Water Crisis in Tanzania's Protected Areas, with Emphasis on the Katuma River-Lake Rukwa Ecosystem.” Ecohydrology and Hydrobiology 10 (2-4): 153-65. https://doi.org/10.2478/v10104-011-00o1-z.

Empinotti, Vanessa Lucena, Jessica Budds, and Marcelo Aversa. 2019. "Governance and Water Security: The Role of the Water Institutional Framework in the 2013-15 Water Crisis in São Paulo, Brazil.” Geoforum 98 (May): 4654. https://doi.org/10.1016/j.geoforum.2018.09.022.

Ferreira, Susane Cristini Gomes, Aline Maria Meiguins de Lima, and José Augusto Martins Corrêa. 2020. "Indicators of Hydrological Sustainability, Governance and Water Resource Regulation in the Moju River Basin (PA) - Eastern Amazonia." Journal of Environmental Management 263 (March). https://doi.org/10.1016/j.jenvman.2020.110354.

Goh, Kian. 2019. "Urban Waterscapes: The Hydro-Politics of Flooding in a Sinking City." International Journal of Urban and Regional Research 43 (2): 250-72. https://doi.org/10.1111/1468-2427.12756.

Hajek, Frank, Marc J. Ventresca, Joel Scriven, and Augusto Castro. 2011. "Regime-Building for REDD+: Evidence from a Cluster of Local Initiatives in South-Eastern Peru." Environmental Science and Policy 14 (2): $201-15$. https://doi.org/10.1016/j.envsci.2010.12.007.

Hanlon, Jeffrey W. 2017. "Complementary Safeguards for Robust Regional Watershed Governance in a Federation: New York City and Its Municipal Water Supply.” Environmental Science and Policy 75 (August 2016): 47-55. https://doi.org/10.1016/j.envsci.2017.04.014.

Hill, Carey, Kathryn Furlong, Karen Bakker, and Alice Cohen. 20o8. "Harmonization Versus Subsidiarity in Water Governance: A Review of Water Governance and Legislation in the Canadian Provinces and Territories." Canadian Water Resources Journal 33 (4): 315-32. https://doi.org/10.4296/cwrj3304315.

Huber-Stearns, Heidi R., and Antony S. Cheng. 2017. "The Evolving Role of Government in the Adaptive Governance of Freshwater Social-Ecological Systems in the Western US.” Environmental Science and Policy 77 (July): 4048. https://doi.org/10.1016/j.envsci.2017.07.011.

Imperial, Mark T. 2005. "Using Collaboration as a Governance Strategy: Lessons from Six Watershed Management Programs.” Administration and Society 37 (3): 281-320. https://doi.org/10.1177/o095399705276111.

Ingold, Karin. 2011. "Network Structures within Policy Processes: Coalitions, Power, and Brokerage in Swiss Climate Policy." Policy Studies Journal 39 (3): 435-59. https://doi.org/10.1111/j.1541-0072.2011.00416.x.

Koontz, Tomas M., and Craig W. Thomas. 2018. "Use of Science in Collaborative Environmental Management: Evidence from Local Watershed Partnerships in the Puget Sound.” Environmental Science and Policy 88 (October): 17-23. https://doi.org/10.1016/j.envsci.2018.06.007.

Lin, Hebin, Jeffrey A. Thornton, and Nickolai Shadrin. 2015. "A Watershed-Based Adaptive Knowledge System for Developing Ecosystem Stakeholder Partnerships.” Chinese Journal of Oceanology and Limnology 33 (6): 147688. https://doi.org/10.1007/soo343-015-4366-5.

Margerum, Richard D. 2008. “A Typology of Collaboration Efforts in Environmental Management.” Environmental Management 41 (4): 487-500. https://doi.org/10.1007/soo267-0o8-9067-9.

Marshall, Amanda C., and Leslie A. Duram. 2017. "Factors Influencing Local Stakeholders' Perceptions of Tisza River Basin Management: The Role of Employment Sector and Education.” Environmental Science and Policy 77 (February): 69-76. https://doi.org/10.1016/j.envsci.2017.07.009.

Medema, Wietske, Alison Furber, Jan Adamowski, Qiqi Zhou, and Igor Mayer. 2016. “Exploring the Potential Impact of Serious Games on Social Learning and Stakeholder Collaborations for Transboundary Watershed Management of the St. Lawrence River Basin." Water (Switzerland) 8 (5). https://doi.org/10.3390/w8050175.

Milman, Anita, and Benjamin P. Warner. 2016. "The Interfaces of Public and Private Adaptation: Lessons from Flooding in the Deerfield River Watershed." Global Environmental Change 36: 46-55. https://doi.org/10.1016/j.gloenvcha.2015.11.007.

Morzaria-Luna, Hem Nalini, Peggy Turk-Boyer, Elia I Polanco-Mizquez, Caroline Downton-Hoffmann, Gabriela Cruz-Piñón, Tonatiuh Carrillo-Lammens, Rene Loaiza-Villanueva, et al. 2020. "Coastal and Marine Spatial Planning in the Northern Gulf of California, Mexico: Consolidating Stewardship, Property Rights, and Enforcement for Ecosystem-Based Fisheries Management." Ocean E Coastal Management 197: 105316. https://doi.org/https://doi.org/10.1016/j.ocecoaman.2020.105316. 
Mumme, Stephen P. 2020. "The 1944 Water Treaty and the Incorporation of Environmental Values in U.S.-Mexico Transboundary Water Governance." Environmental Science $\mathcal{E}$ Policy 112: 126-33. https://doi.org/https://doi.org/10.1016/j.envsci.2020.05.001.

Oliveira Faria, Claudia de, and Alessandra Magrini. 2016. "Biodiversity Governance from a Cross-Level and CrossScale Perspective: The Case of the Atlantic Forest Biome in Brazil." Environmental Policy and Governance 26 (6): 468-81. https://doi.org/10.1002/eet.1728.

Overduin, Natasha, and Michele Lee Moore. 2017. "Social License to Operate: Not a Proxy for Accountability in Water Governance." Geoforum 85 (June 2016): 72-81. https://doi.org/10.1016/j.geoforum.2017.07.008.

Patricia E. Perkins, Jackie Peat. 2017. "Gender in Climate Justice in Canda: Stories from the Grassroots," 1-72.

Patterson, Lauren A., Jeffrey Hughes, Glenn Barnes, and Stacey I. Berahzer. 2012. "A Question of Boundaries: The Importance of 'Revenuesheds' for Watershed Protection." Journal of the American Water Resources Association 48 (4): 838-48. https://doi.org/10.1111/j.1752-1688.2012.00655.x.

Pellegrini, Emilia, Lucia Bortolini, and Edi Defrancesco. 2019. "Coordination and Participation Boards under the European Water Framework Directive: Different Approaches Used in Some EU Countries.” Water (Switzerland) 11 (4): 1-22. https://doi.org/10.3390/w11040833.

Rathwell, Kaitlyn J., and Garry D. Peterson. 2012. "Connecting Social Networks with Ecosystem Services for Watershed Governance: A Social-Ecological Network Perspective Highlights the Critical Role of Bridging Organizations." Ecology and Society 17 (2). https://doi.org/10.5751/ES-04810-170224.

Richards, Ryan C., Chris J. Kennedy, Thomas E. Lovejoy, and Pedro H.S. Brancalion. 2017. "Considering Farmer Land Use Decisions in Efforts to 'Scale up' Payments for Watershed Services.” Ecosystem Services 23 (October 2016): 238-47. https://doi.org/10.1016/j.ecoser.2016.12.016.

Schweizer, Daniella. 2017. "Stakeholder Perceptions on Governance for the Protection and Increase of Forest Cover in the Panama Canal Watershed." World Development Perspectives 6: 11-13. https://doi.org/10.1016/j.wdp.2017.03.005.

Siders, A. R. 2019. "Adaptive Capacity to Climate Change: A Synthesis of Concepts, Methods, and Findings in a Fragmented Field." Wiley Interdisciplinary Reviews: Climate Change 10 (3). https://doi.org/10.1002/wcc.573.

Sikka, Alok K. 2009. "Exploring Options of Participatory Water Management for Livelihood Improvements in the Indo-Gangetic Basin.” International Journal of River Basin Management 7 (2): 147-55. https://doi.org/10.1080/15715124.2009.9635377.

Sugiyono. 2016. A t a Watershed, Ecological Governance and Sustainable Water Management in Canda. Library and Archives Canada Cataloguing in Publication Data At. https://doi.org/10.1017/CBO9781107415324.004.

Ulibarri, Nicola, and Nataly Escobedo Garcia. 2020. "Comparing Complexity in Watershed Governance: The Case of California.” Water (Switzerland) 12 (3). https://doi.org/10.339o/w12030766.

Wang, Longfei, Jiaxin Tong, and Yi Li. 2019. "River Chief System (RCS): An Experiment on Cross-Sectoral Coordination of Watershed Governance." Frontiers of Environmental Science and Engineering 13 (4): 10-12. https://doi.org/10.1007/s11783-019-1157-9.

Ward, Lucas, Matthew B. Anderson, Susan J. Gilbertz, Jamie McEvoy, and Damon M. Hall. 2017. "Public Stealth and Boundary Objects: Coping with Integrated Water Resource Management and the Post-Political Condition in Montana's Portion of the Yellowstone River Watershed." Geoforum 83 (October 2016): 1-13. https://doi.org/10.1016/j.geoforum.2017.04.017.

Weible, Christopher M. 2011. "Political-Administrative Relations in Collaborative Environmental Management." International Journal of Public Administration 34 (7): 424-35. https://doi.org/10.108o/o1900692.2011.569916.

Zeitoun, Mark, Marisa Goulden, and David Tickner. 2013. "Current and Future Challenges Facing Transboundary River Basin Management.” Wiley Interdisciplinary Reviews: Climate Change 4 (5): 331-49. https://doi.org/10.1002/wcc.228. 